
\title{
$\begin{array}{ll}\text { Research Square } & \begin{array}{l}\text { Preprints are preliminary reports that have not undergone peer review. } \\ \text { They should not be considered conclusive, used to inform clinical practice, } \\ \text { or referenced by the media as validated information. }\end{array}\end{array}$ \\ Evaluation and prioritisation of potential locations for investment in dental tourism
}

\section{Fatemeh Ahmadimanesh}

Babol Noshirvani University of Technology

Mohammad Pourmehdi

Babol Noshirvani University of Technology

Mohammad Mahdi Paydar ( $\sim$ paydar@nit.ac.ir)

Babol Noshirvani University of Technology https://orcid.org/0000-0002-0941-247X

\section{Research Article}

Keywords: Dental Tourism, Investment, Location Selection, DEMATEL, DANP, VIKOR

Posted Date: June 7th, 2021

DOl: https://doi.org/10.21203/rs.3.rs-211614/v1

License: (1) This work is licensed under a Creative Commons Attribution 4.0 International License.

Read Full License

Version of Record: A version of this preprint was published at Soft Computing on August 17th, 2021. See the published version at https://doi.org/10.1007/s00500-021-06124-2. 


\title{
Evaluation and prioritisation of potential locations for investment in dental tourism
}

\author{
Fatemeh Ahmadimanesh \\ Department of Industrial Engineering, Babol Noshirvani University of Technology, Babol, Iran, \\ fahmadi62@yahoo.com \\ Mohammad Pourmehdi \\ Department of Industrial Engineering, Babol Noshirvani University of Technology, Babol, Iran, \\ mopourmehdi@gmail.com \\ Mohammad Mahdi Paydar ${ }^{1}$ \\ Department of Industrial Engineering, Babol Noshirvani University of Technology, Babol, Iran, \\ paydar@nit.ac.ir
}

\begin{abstract}
Medical tourism had notable growth in the past few years, and it is understood that one of the most prevalent types of medical tourism is dental tourism. This study aims to select the most suitable city for investment in dental tourism. Five dimensions and nineteen criteria associated with dental tourism have been specified, and the DEMATEL-based ANP (DANP) is used to determine the interrelation of criteria and compute their weights. Then, the VIKOR is used to evaluate the suitability of different cities for investment in dental tourism and determine the potential areas of the selected cities that need enhancement. A case study is conducted to present the applicability of the suggested model. The results indicate that the dental facilities and service is the most critical dimension, and reputation of hospital/facility and doctors, dental clinics with certification/accreditation scheme are the most important criteria for analysing the suitability of potential locations.
\end{abstract}

Keywords: Dental Tourism, Investment, Location Selection, DEMATEL, DANP, VIKOR

\section{Introduction}

Travelling overseas and seeking high-quality healthcare service and treatment is not a new phenomenon. Traditionally, wealthy people from developing countries travelled to developed countries to receive medical treatment. Recently, this trend is reversed through travelling of more people from developed to developing countries seeking high-quality medical care with low costs (Wachter, 2006; Alleman et al., 2011; Wong and Musa, 2012). In the past few decades, medical tourism has become one of the fastest-growing and most popular trends in both the healthcare and tourism industry. According to the World Tourism Organization, medical tourism is defined as travelling with the primary purpose of treating physical illnesses or getting operated on by doctors in a hospital or medical centre. These kinds of trips have become more prevalent for different reasons such as globalisation of trade, changes in exchange rates, and subsequently restrictions for

${ }^{1}$ Corresponding author; Phone number: +98 $9113235979 \mathrm{z}$ 
Asian countries and economic crises. Tourists seek various kinds of medical services such as skincare, diet program, tooth whitening, dental fillings, wrinkle removal, and also complex operations such as cardiac surgery, cancer treatment, orthopaedic surgery, ophthalmologic care, organ and cellular transplantation, and gender reassignment procedures (Horowitz et al., 2007; Reddy et al., 2010). Numerous countries worldwide and especially in Asia, are eager to find potential areas for investment in the growing market of medical tourism to enhance their revenue and subsequently improve their economy. Hence, the participation of governments in expanding the market for medical tourism in high potential countries and attracting tourists became common (Whittaker, 2008).

Dental tourism is a subset of medical tourism, which involves tourists seeking destinations with low costs and high-quality dental service providers, which also might be accompanied by spending their vacation. Nowadays, dental tourism is rapidly growing, making the residents of developed countries choose developing countries as their destination for dental tourism. The most common reason for travelling from one country to another is the high cost of dental treatment in the home country of patients in a way that combined costs of travelling, accommodations, and even entertainment and treatment would be less than the cost of treatment in the home country of tourists. The unavailability of a specific speciality in the home country of tourist could be another reason for the growth of this industry.

Even though countries that have popular tourism services try to deliver medical services to expand their market, the capability of a country in medical science and service is not the thing that could be improved merely by spending money and construction, unlike recreational and sports tourism. The availability of experienced doctors, required infrastructure, hospitals and standard clinics, medical science background, up-to-date medical equipment, and the regulation and medical supervisory are among the most important requirements for a potential country as a destination for medical tourism. Only after having these requirements a country can integrate its tourism services with medical service to serve as a suitable destination for medical tourism. It should be mentioned that the medical background of Iran goes back thousands of years, and Iranian doctors are always renowned at international levels (Alizadeh et al., 2020). Regardless of the potentials of Iran in medical tourism, this industry is growing haphazardly, and it could be said that it does not have a clear path ahead of it. If this industry does not get properly managed, its potential would be wasted (Tourism Research and Marketing, 2006). Iran is mainly relying on the export of oil for its gross domestic product (GDP). In order to reduce the dependence of the GDP on the oil industry, it can invest in other products and services that can have a positive influence on its GDP (Pourmehdi et al., 2021). Medical tourism is one of the potential areas for reducing the dependence of GDP on the oil industry because it requires low cost and generates significant revenue, and the structure of the healthcare of the country would enhance, causing economic growth. Moreover, Iran has the potential to become successful in medical tourism having the required amenities such as low cost of treatment, experienced and expert human resources, proper social and cultural features, and required infrastructure.

This study presents a decision-making model specifying the most significant criteria for choosing a location as the most suitable location for investment in dental tourism and subsequently select the most suitable locations considering the significance of dental tourism and the difference in the 
suitability of different locations for investment. To this extent, in the first step, the most relevant criteria influencing dental tourism are extracted from the literature review, and then they are categorised into five dimensions regarding the opinion of experts in dental tourism and the relevance of the criteria. In the next step, the nineteen specified criteria are prioritised by a decision-making model using a combination of multi-criteria decision making (MCDM) methods, considering the effectiveness of the hybrid MCDM approaches (Khatwani and Srivastava, 2018). The DEMATEL is used to determine the interrelation of criteria, and then the DANP is employed to calculate their weights. Finally, VIKOR is used to evaluate the suitability of different cities for investment in dental tourism and determine the potential areas of the selected cities that need enhancement. In the final step, a real case study addressing some potential cities in Iran is presented. Iran is selected because of the significance of dental tourism in the country and its potential in becoming one of the most suitable destinations for dental tourists.

The outline of the study is mentioned in the following. In the next section, the literature review of medical and dental tourism is presented. The introduction and explanations regarding the DEMATEL, DANP, and VIKOR are presented in section 3. In section 4, the case study for showing the applicability of the suggested decision-making model, the final results of the case study and discussion of results are presented. Finally, the conclusion of the study is presented in section 5 .

\section{Related studies}

The previous studies related to this research could be divided into two sections, including the literature regarding medical tourism and dental tourism, focusing on quantitative studies.

\subsection{Medical tourism}

The constant change and development of technology, specifically in transportation and medical treatment, is creating new ways for people to meet their needs for medical operations in various ways. These changes are happening faster than ever in the current time, increasing the number of people willing to travel from their home countries to other countries for healthcare related operations (Fetscherin and Stephano, 2016). The concept of medical tourism has been developed to help the countries that have the potential to become a destination for patients who intend to these countries to meet their medical demands (Momeni et al., 2018). Some of the recent studies that investigated different aspects of medical tourism are presented in the following.

Heung et al. (2011) presented a study with the main goal of determining the most influential factors in the process of developing medical tourism in Hong Kong. They also suggested several strategies for addressing the main challenges in the way of developing medical tourism. A study aiming to investigate the factors affecting the selection of destination in infertile couples referred to a Fertility and Infertility Center in Isfahan, Iran, was conducted by Moghimehfar and Nasr-Esfahani (2011). Yu and Ko (2012) investigated the factors considering the perceptions and participation in medical tourism by Korean, Japanese, and Chinese tourists visiting Jeju Island in Korea, aiming to specify cultural differences between them and the way those differences influence their pursuit of medical tourism. Pan and Chen (2014) explored the perceptions and motivations of tourists from 
China visiting Taiwan regarding the quality of medical tourism services and packages. A model exploring the intention of international medical tourists arising from the significance of the trust, satisfaction, quality, and reasonableness of price, which affect the willingness of tourists to revisit the destination country and clinics, was developed by Han and Hyun (2015). Lee and Fernando (2015) developed a model investigating the medical tourism supply chain of Malaysia with the antecedents and outcomes using a self-administered questionnaire.

Fetscherin and Stephano (2016) conducted a study with the purpose of presenting the medical tourism index as a performance measurement tool for assessing the attractiveness of countries as a destination for medical tourists. Ganguli and Ebrahim (2017) analysed and identified factors that indicate the attractiveness of Singapore as a medical tourism destination. Their study showed that the integration of proactive management practices with sound government policies and medical tourism development would significantly enhance the success of healthcare, tourism, and economic sectors. Esiyok et al. (2017) presented a study analysing the relationships between the cultural distance of the home and destination countries of international patients in the medical tourism context. A study exploring the potential for the development of domestic medical tourism in the Sunshine Coast of Australia was conducted by Tham (2018). The research showed that issues like access of residents to hospital facilities, hostile attitudes between practitioners, and lack of cooperation were barriers to the development of medical tourism in that area. Momeni et al. (2018) presented a study with the main purpose of determining the barriers to the development of medical tourism in the East Azerbaijan province of Iran. A study aiming to identify the factors influencing the development of medical tourism in a developing country was conducted by Nilashi et al. (2019). They determined that technological and human factors are the most significant ones for the adoption of medical tourism in Malaysia.

\subsection{Dental tourism}

Travelling overseas and seeking convenient dental treatments is known as the most common form of medical tourism (Lovelock et al., 2018). The studies that specifically investigated different aspects of dental tourism are presented in the following.

Österle et al. (2009) presented a study to analyse Hungary, which is one of the most famous destination countries, regarding its dental care tourism profile using a questionnaire-based analysis. Another study considering Hungary as the case study with the purpose of providing extensive empirical evidence from the viewpoint of a recipient country in dental care tourism was presented by Kovacs and Szocska (2013). Kamath et al. (2015) explored and addressed the economic, ethical, social, and legal aspects of dental tourism in India. Adams et al. (2017) analysed the outcome of interviews with dental tourism industry agents who worked in Los Algodones, Mexico, to explore the support of participants regarding the industry site reputational management. A study measuring tourist travel motivations, profiles, and satisfaction between inbound dental tourists in Malaysia was presented by Jaapar et al. (2017). They specified dental care quality, costsaving, and dental care information as the primary motivating factors.

Adams et al. (2018) examined the perspectives and experiences of industry stakeholders in northern Mexico. The main goal of their study was to develop a clearer understanding of the effects of common discourses and the possible implications of the practices on health equity. Lovelock et 
al. (2018) conducted a study to preserve the impacts of dental tourism on a specific region based on an email survey of the dental care community in New Zealand. A study exploring the factors influencing the decision of patients on attaining profit from dental services in Albania was conducted by Nexhipi (2018). Ahmadimanesh et al. (2019) suggested a mathematical model for presenting the optimal design of a dental tourism supply chain network considering medical facilities, accommodations, and tourists. They aimed to determine the optimal number and capacity of medical and accommodation units. A study with the primary goal of providing comprehensive empirical evidence from the perspective of the dental clinics and tourism agencies in Romanian dental tourism was presented by Oltean et al. (2020). The results of their study indicated that dental tourism and tourism agencies are interested in investing, promoting, and creating a partnership to create a sustainable industry of dental tourism.

\section{Methodology}

The methodology utilised for the primary goal of ranking potential locations for investment in dental tourism is explored in this section. The proposed methodology has four phases, naming preevaluation, DEMATEL, DANP, and VIKOR. The first phase is the identification of potential locations and specifying the potential dimensions and criteria, using the assistance of qualified experts. The next three phases present the determination of the influential network relations map (INRM), the influential weights of criteria, and the final ranking of the alternatives, respectively. The processes of the methodology are summarised in Fig. 1, and each phase is explored in detail in the following sub-sections. 


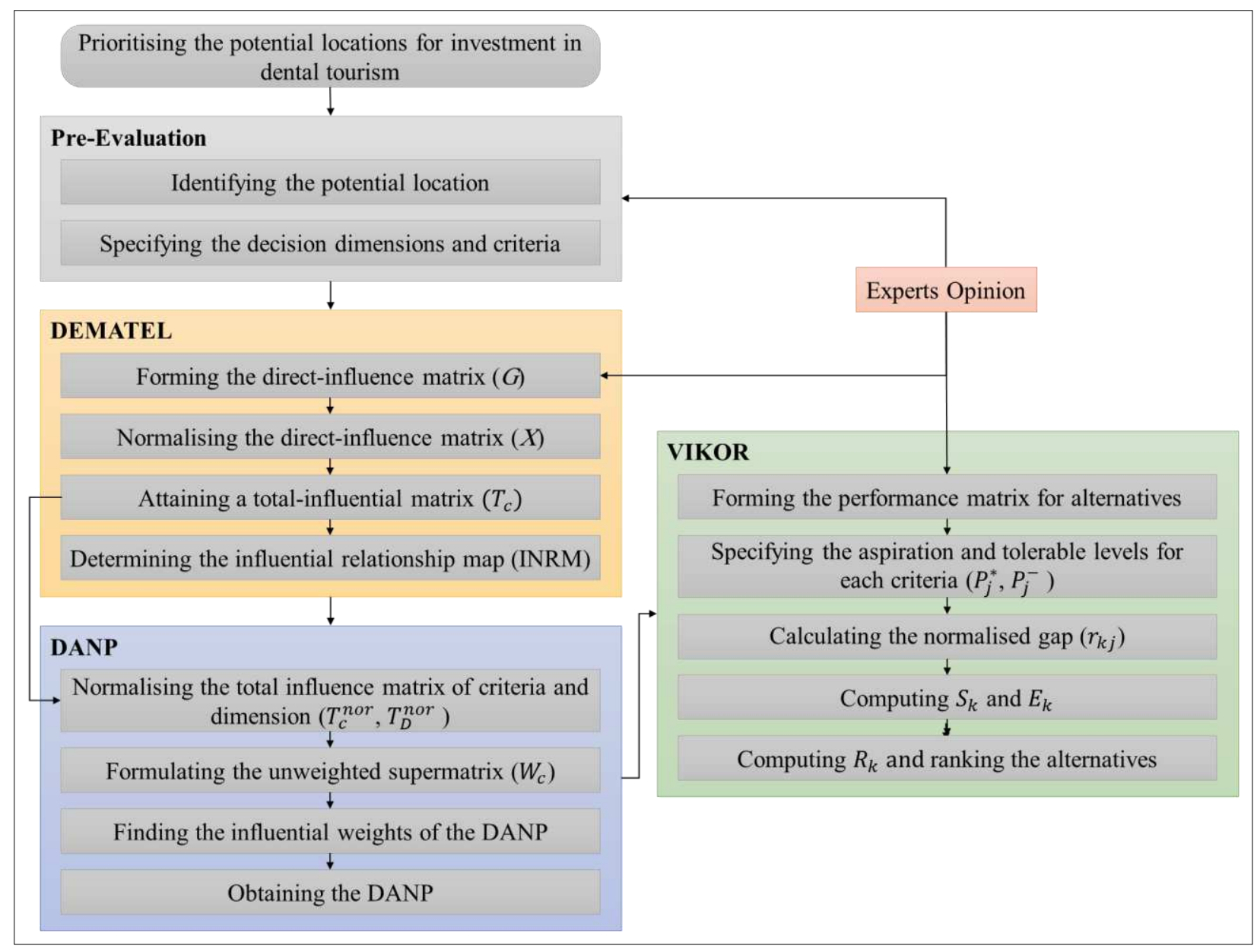

Figure 1. The framework of the methodology

\subsection{Pre-Evaluation}

Determining the most relevant criteria is one of the most critical parts of evaluation and prioritisation of a specific set of alternatives (Fabisiak, 2018). Hence the selection of criteria should be made by qualified experts, and these experts themselves should be carefully selected having a specific set of characteristics (Zhang et al., 2019). The first step in the selection of qualified experts would be determining their qualification. The most important qualification is that they should be employees of well-known medical/dental tourism agencies with more than five years of experience in their position. They should also be in a position that is constantly connected with the customers of the agency so they would be familiar with the mindset of customers regarding their needs.

After the selection of qualified experts, a set of criteria and dimensions were extracted from the literature. Then the lists of criteria were presented to the experts and based on their opinions, some criteria were selected as the most relevant criteria to the problem and put into the selected dimensions. The five selected dimensions for categorising the criteria used in ranking the potential locations for investment in dental tourism are general infrastructure, tourism infrastructure, dental facilities and service, environment and natural resources, and culture and art. The experts were then asked to fill the presented questionnaires to them, determining the interrelation of criteria and 
their weights, and finally, the ranking of alternatives. The dimensions, criteria, the allocated codes to them, and the references of each criterion are mentioned in Table 1.

Table 1. Decision dimensions and criteria

\begin{tabular}{|c|c|c|}
\hline Dimensions & Criteria & References \\
\hline \multirow{3}{*}{$\begin{array}{l}\text { General } \\
\text { infrastructure } \\
(\mathrm{GI}) \\
\end{array}$} & Development of Public and private transportation (GI1) & (Beerli and Martín, 2004) \\
\hline & Development of telecommunications (GI2) & (Beerli and Martín, 2004) \\
\hline & Development of commercial infrastructures (GI3) & (Beerli and Martín, 2004) \\
\hline \multirow{4}{*}{$\begin{array}{l}\text { Tourism } \\
\text { infrastructure } \\
(\mathrm{TI})\end{array}$} & Quality and quantity of accommodations (TI1) & (Beerli and Martín, 2004) \\
\hline & Entertainment and sports activities & (Beerli and Martín, 2004) \\
\hline & Quality and quantity of restaurants (TI3) & (Beerli and Martín, 2004) \\
\hline & Travel and tourism agencies (TI4) & (Yu and Ko, 2012) \\
\hline \multirow{4}{*}{$\begin{array}{l}\text { Dental facilities } \\
\text { and service (DS) }\end{array}$} & $\begin{array}{l}\text { Dental clinic with certification/accreditation scheme } \\
\text { (DS1) }\end{array}$ & $\begin{array}{l}\text { (Elliott-Smith, 2010; Fetscherin } \\
\text { and Stephano, 2016) }\end{array}$ \\
\hline & Qualified and competent dental professionals (DS2) & $\begin{array}{l}\text { (Turner, 2008; Ungureanu and } \\
\text { Mocean, 2015) }\end{array}$ \\
\hline & High quality/standard of dental care (DS3) & $\begin{array}{l}\text { (Fetscherin and Stephano, 2016; } \\
\text { Kovacs and Szocska, 2013; } \\
\text { Österle et al., 2009; Turner, 2008) }\end{array}$ \\
\hline & Reputation of hospital /facility and doctors (DS4) & $\begin{array}{l}\text { (Fetscherin and Stephano, 2016; } \\
\text { Heung et al., 2011) }\end{array}$ \\
\hline \multirow{4}{*}{$\begin{array}{l}\text { Environment and } \\
\text { natural resources } \\
(\mathrm{EN})\end{array}$} & Weather (Temperature, humidity, and rainfall) (EN1) & (Beerli and Martín, 2004) \\
\hline & Beauty of the scenery (EN2) & (Beerli and Martín, 2004) \\
\hline & Traffic congestion and air and noise pollution (EN3) & (Beerli and Martín, 2004) \\
\hline & Safety (Crime rates) (EN4) & (Beerli and Martín, 2004) \\
\hline \multirow{4}{*}{$\begin{array}{l}\text { Culture and art } \\
\text { (CA) }\end{array}$} & Museums, historical buildings, and monuments (CA1) & (Beerli and Martín, 2004) \\
\hline & Festival, concerts, etc. (CA2) & (Beerli and Martín, 2004) \\
\hline & Handicraft and gastronomy (CA3) & (Beerli and Martín, 2004) \\
\hline & Attractiveness of the cities and towns (CA4) & (Beerli and Martín, 2004) \\
\hline
\end{tabular}

\subsection{DEMATEL}

DEMATEL can use the opinion of experts and present an INRM, showing the interdependence of elements of a system (Wu et al., 2020). The practicality of the DEMATEL in presenting an INRM method is proved by the frequency of its application separately and integrated with other MCDM methods in versatile research areas ( $\mathrm{Si}$ et al., 2018). The steps of the method utilised to develop the INRM are presented in the following (Liou et al., 2007).

\section{Step 1: Forming the direct-influence matrix $(G)$}

The direct-influence matrix is formed through the opinion of experts using a scale with a range from 0 to 4, meaning no influence and powerful influence, respectively. Experts give their opinion about the influence of one element on other elements and vice versa by pairwise comparison, and their judgments form the direct-influence matrix. Since there is more than one expert, each element of the matrix represents the arithmetic mean of the opinion of all experts. 


$$
G=\left[\begin{array}{ccccc}
g_{11} & \cdots & g_{1 j} & \cdots & g_{1 n} \\
\vdots & & \vdots & & \vdots \\
g_{i 1} & \cdots & g_{i j} & \cdots & g_{i n} \\
\vdots & & \vdots & & \vdots \\
g_{n 1} & \cdots & g_{n j} & \cdots & g_{n n}
\end{array}\right]_{n \times n}
$$

$n$ is the number of elements.

\section{Step 2: Normalising the direct-influence matrix $(X)$}

The direct-influence matrix is normalised through Eq. (2).

$$
X=v G, \text { where } v=\min _{i, j}\left\{1 / \max _{i} \sum_{j=1}^{n} g_{i j}, 1 / \max _{j} \sum_{i=1}^{n} g_{i j}\right\}, i, j \in\{1,2, \ldots, n\}
$$

Step 3: Attaining a total-influential matrix $\left(\boldsymbol{T}_{c}\right)$

The total-influential matrix is attained by using Eq. (3).

$$
\begin{aligned}
T_{c} & =X+X^{2}+X^{3}+\cdots+X^{l} \\
& =X\left(I+X+X^{2}+\cdots+X^{l-1}\right)(I-X)(I-X)^{-1} \\
& =X\left(I-X^{l}\right)(I-X)^{-1}=X(I-X)^{-1}, \text { when } \lim _{l \rightarrow \infty} X^{l} \\
& =[0]_{n \times n}
\end{aligned}
$$

$I$ is the identity matrix and $X=\left[x_{i j}\right]_{n \times n}, 0 \leq x_{i j}<1,0<\sum_{j=1}^{n} x_{i j}<1,0<, \sum_{i=1}^{n} x_{i j}<1$

\section{Step 4: Determining the influential network relations map (INRM)}

The INRM is determined by computing the values of $\left(r_{i}+s_{i}\right)$ and $\left(r_{i}-s_{i}\right)$ from the total influence matrix. 


$$
\begin{aligned}
& \begin{array}{lllll}
D_{1} & \cdots & D_{j} & \cdots & D_{m}
\end{array} \\
& c_{11 \ldots} c_{1 n_{1}} \quad \cdots \quad c_{j 1 \ldots} c_{j n_{j}} \quad \cdots \quad c_{m 1 \ldots} \ldots c_{m n_{m}}
\end{aligned}
$$

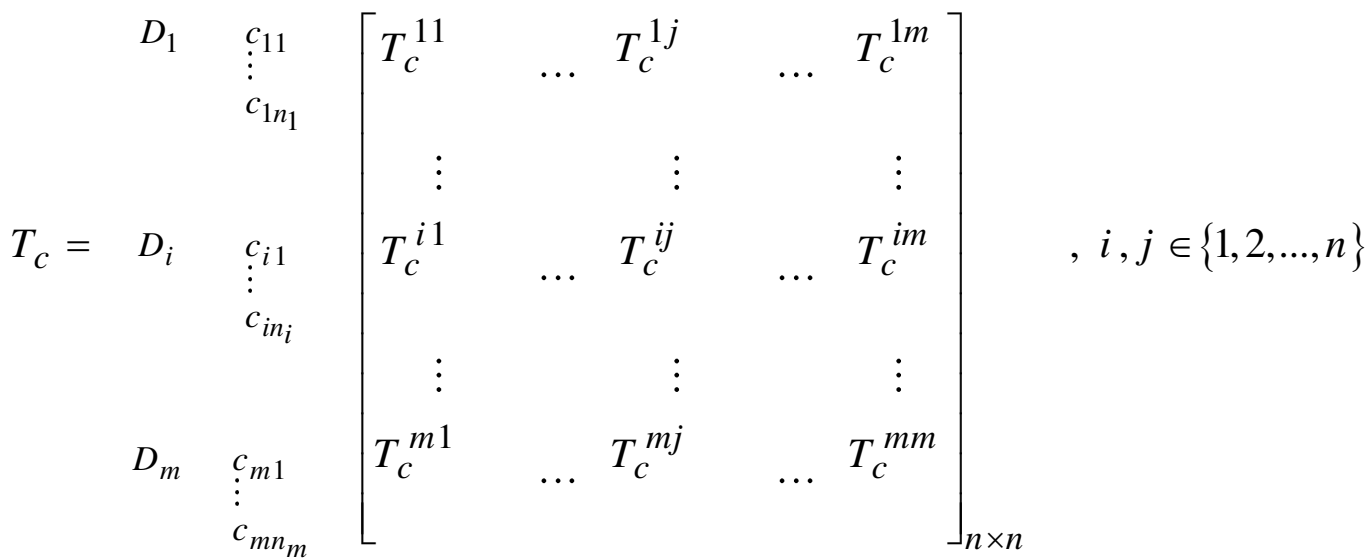

$$
\begin{aligned}
& r=\left[\sum_{j=1}^{n} t_{c}^{i j}\right]_{n \times 1}=\left[t_{c}^{i}\right]_{n \times 1}=\left(r_{1}, \ldots, r_{i}, \ldots, r_{n}\right) \\
& s=\left[\sum_{i=1}^{n} t_{c}^{i j}\right]_{1 \times n}^{\prime}=\left[t_{c}^{j}\right]_{n \times 1}=\left(s_{1}, \ldots, s_{j}, \ldots, s_{n}\right) \text {, superscript ' denotes transpose }
\end{aligned}
$$

Let $i=j \in\{1,2, \ldots, n\}$. The horizontal axis vector is determined by adding $r_{i}$ to $s_{i}$, to represent the importance of the criterion, and the vertical axis vector is determined by subtracting $r_{i}$ from $s_{i}$, dividing the criteria into cause or effect clusters. Positive $\left(r_{i}-s_{i}\right)$ indicates that the criterion is in the cause group, meaning that this criterion affects other criteria. In contrast, the negative value of $\left(r_{i^{-}}\right.$ $s_{i}$ ) means that the criterion is in the effect group, indicating that this criterion is influenced by other criteria. Hence, the graph naming INRM can be designed by mapping the data set of $\left(r_{i}+s_{i}, r_{i}-s_{i}\right)$, to decide how the selected values in each dimension and criterion can be improved.

\subsection{DANP}

The ANP method proposed by Saaty and Vargas (Saaty and Vargas, 2006) has a few shortcomings naming complicated and time-consuming processes of filling the questionnaires and the assumption of equal weights for each cluster in obtaining weighted supermatrix. In order to deal with these issues, the DEMATEL is integrated with the ANP, and a DEMATEL-based ANP naming the DANP is formed (Dinçer et al., 2020). This method uses the INRM of DEMATEL to determine the influential weights of the criteria. The DANP has been widely utilised in various areas of research (Chen and Lin, 2018; Titiyal et al., 2019; Li et al., 2020). The steps of the approach applied for calculating the influential weights of criteria are outlined in the following (Chiu et al., 2013).

\section{Step 1: Normalising the total influence matrix of criteria and dimension $\left(T_{c}^{n o r}, T_{D}^{n o r}\right)$}

The total influence matrix of dimension and criteria are obtained using Eqs (7)-(11). 


$$
\begin{aligned}
& T_{D}^{n o r}=\left[\begin{array}{ccccc}
t_{D}^{n o r_{11}} & \cdots & t_{D}^{n o r_{1 j}} & \cdots & t_{D}^{n o r_{1 m}} \\
\vdots & & \vdots & & \vdots \\
t_{D}^{n o r_{i 1}} & \cdots & t_{D}^{n o r_{i j}} & \cdots & t_{D}^{n o r_{i m}} \\
\vdots & & \vdots & & \vdots \\
t_{D}^{n o r_{m 1}} & \cdots & t_{D}^{n o r_{m j}} & \cdots & t_{D}^{n o r_{m m}}
\end{array}\right]=\left[\begin{array}{ccccc}
t_{D}^{11} / t_{D}^{1} & \cdots & t_{D}^{1 j} / t_{D}^{1} & \cdots & t_{D}^{1 m} / t_{D}^{1} \\
\vdots & & \vdots & & \vdots \\
t_{D}^{i 1} / t_{D}^{i} & \cdots & t_{D}^{i j} / t_{D}^{i} & \cdots & t_{D}^{i m} / t_{D}^{i} \\
\vdots & & \vdots & & \vdots \\
t_{D}^{m 1} / t_{D}^{m} & \cdots & t_{D}^{m j} / t_{D}^{m} & \cdots & t_{D}^{m m} / t_{D}^{m}
\end{array}\right] \\
& T_{D}=\left[\begin{array}{ccccc}
t_{D}^{11} & \cdots & t_{D}^{1 j} & \cdots & t_{D}^{1 m} \\
\vdots & & \vdots & & \vdots \\
t_{D}^{i 1} & \cdots & t_{D}^{i j} & \cdots & t_{D}^{i m} \\
\vdots & & \vdots & & \vdots \\
t_{D}^{m 1} & \cdots & t_{D}^{m j} & \cdots & t_{D}^{m m}
\end{array}\right] \rightarrow \sum_{j=1}^{m} t_{D}^{1 j}=t_{D}^{1} \\
& \begin{array}{lllll}
D_{1} & \cdots & D_{j} & \cdots & D_{m}
\end{array} \\
& c_{11 \ldots} \ldots c_{1 n_{1}} \quad \cdots \quad c_{j 1 \ldots} c_{j n_{j}} \quad \cdots \quad c_{m 1 \ldots} c_{m n_{m}}
\end{aligned}
$$

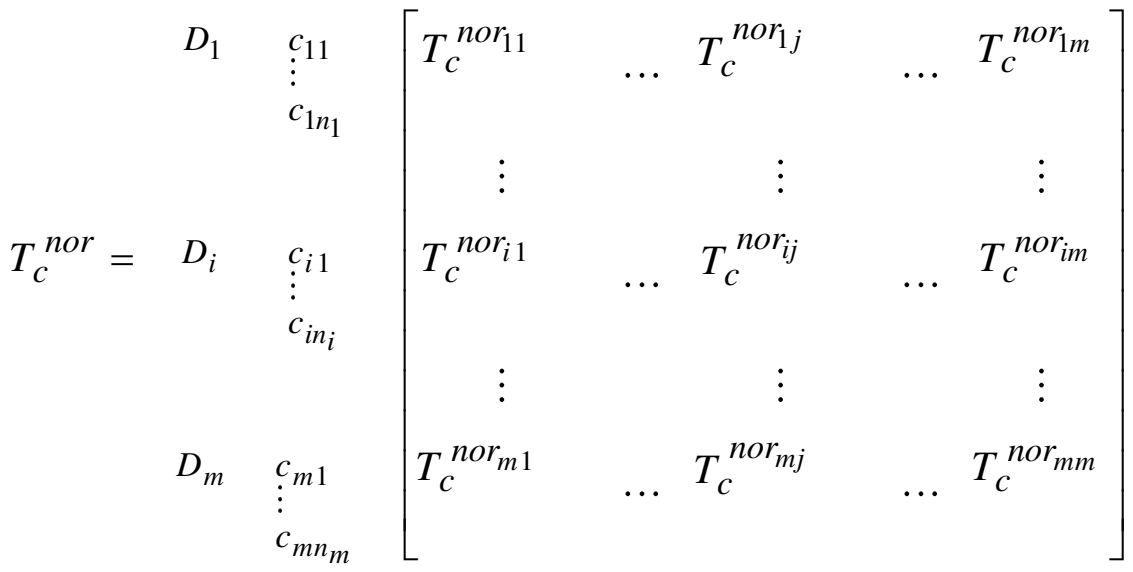




$$
\begin{aligned}
& T_{c}^{n o r_{11}}=\left[\begin{array}{ccccc}
t_{c_{11}}^{n o r_{11}} & \cdots & t_{c_{1 j}}^{n o r_{11}} & \cdots & t_{c_{1 n_{1}}}^{n o r_{11}} \\
\vdots & & \vdots & & \vdots \\
t_{c_{i 1}}^{n o r_{11}} & \cdots & t_{c_{i j}}^{n o r_{11}} & \cdots & t_{c_{i n_{1}}}^{n o r_{11}} \\
\vdots & & \vdots & & \vdots \\
t_{c_{n_{1} 1}^{n o r_{11}}}^{n} & \cdots & t_{c_{n_{1} j}}^{n o r_{11}} & \cdots & t_{c_{n_{1} n_{1}}}^{n o r_{11}}
\end{array}\right] \\
& =\left[\begin{array}{ccccc}
t_{c_{11}}^{11} / t_{c_{1}}^{11} & \cdots & t_{c_{1 j}}^{11} / t_{c_{1}}^{11} & \cdots & t_{c_{1 n_{1}}}^{11} / t_{c_{1}}^{11} \\
\vdots & & \vdots & & \vdots \\
t_{c_{i 1}}^{11} / t_{c_{i}}^{11} & \cdots & t_{c_{i j}}^{11} / t_{c_{i}}^{11} & \cdots & t_{c_{n_{1}}}^{11} / t_{c_{i}}^{11} \\
\vdots & & \vdots & & \vdots \\
t_{c_{n_{1} 1}}^{c_{11}} / t_{c_{n_{1}}}^{11} & \cdots & t_{c_{n_{1} j}}^{11} / t_{c_{n_{1}}}^{11} & \cdots & t_{c_{n_{1} n_{1}}}^{11} / t_{c_{n_{1}}}^{11}
\end{array}\right] \\
& t_{c_{i}}^{11}=\sum_{j=1}^{n_{i}} t_{c_{i j}}^{11}, \forall i=\left\{1,2, \ldots, n_{i}\right\}
\end{aligned}
$$

Step 2: Formulating the unweighted supermatrix $\left(W_{c}\right)$

$$
\begin{aligned}
& \begin{array}{lllll}
D_{1} & \cdots & D_{j} & \cdots & D_{m}
\end{array} \\
& c_{11 \ldots} c_{1 n_{1}} \quad \cdots \quad c_{j 1 \ldots} c_{j n_{j}} \quad \cdots \quad c_{m 1} \ldots c_{m n_{m}}
\end{aligned}
$$

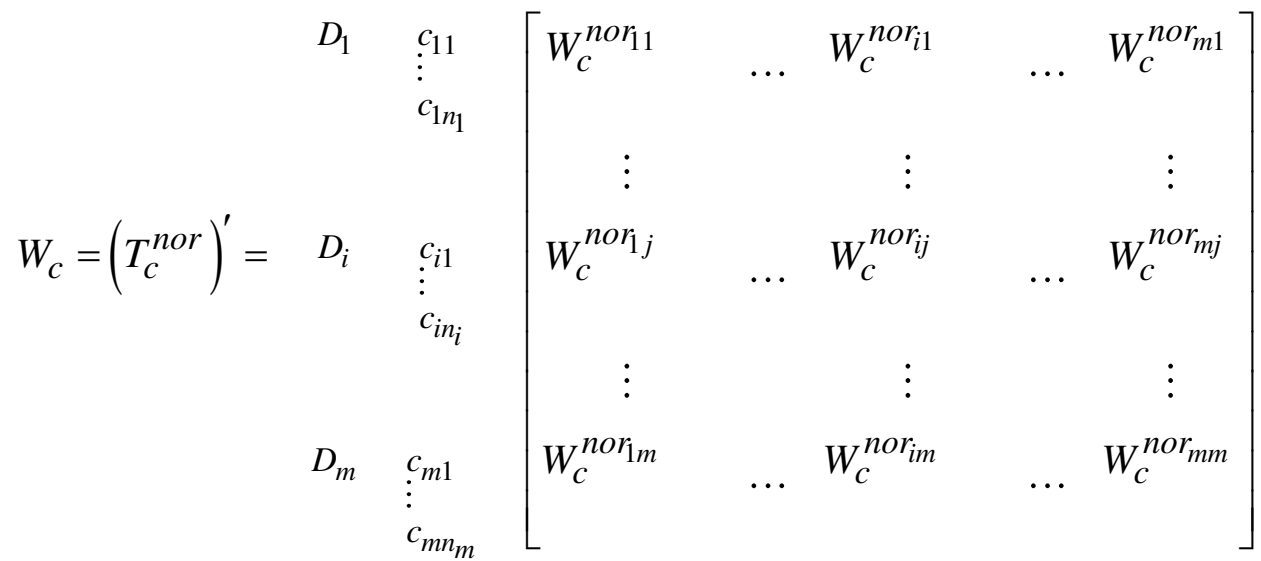

Step 3: Finding the influential weights of the DANP 


$$
W_{c}^{*}=T_{D}^{n o r} \cdot W_{c}\left[\begin{array}{cccccc}
t_{D}^{n o r_{11}} \times W_{c}^{11} & \cdots & t_{D}^{n o r_{11}} \times W_{c}^{i 1} & \cdots & t_{D}^{n o r_{m 1}} \times W_{c}^{m 1} \\
\vdots & & \vdots & & \vdots \\
t_{D}^{n o r_{1 j}} \times W_{c}^{1 j} & \cdots & t_{D}^{n o r_{i j}} \times W_{c}^{i j} & \cdots & t_{D}^{n o r_{m j}} \times W_{c}^{m j} \\
\vdots & & \vdots & & \vdots \\
t_{D}^{n o r_{1 m}} \times W_{c}^{1 m} & \cdots & t_{D}^{n o r_{i m}} \times W_{c}^{i m} & \cdots & t_{D}^{n o r_{m m}} \times W_{c}^{m m}
\end{array}\right]
$$

\section{Step 4: Obtaining the DANP}

The global priority vectors, which represent the influential weights, are obtained by limiting the weighted supermatrix and raising it to a sufficiently large power so it converges and becomes a long-term stable supermatrix.

$$
\lim _{\alpha \rightarrow \infty}\left(W_{c}^{*}\right)^{\alpha} \rightarrow w=\left(w_{1}, w_{2}, \ldots, w_{n}\right)
$$

\subsection{VIKOR}

The VIKOR, or in other words, compromise ranking method proposed by Opricovic and Tzeng (2007), focusing on ranking and prioritising alternatives from a predetermined set regarding the conflicting different criteria (Ashtiani and Abdollahi Azgomi, 2016). The ranking process is done through a ranking index, considering the closeness of alternatives to the ideal solution (Chiu et al., 2013). The steps of the method utilised to find the final ranking of the alternatives are presented in the following (Titiyal et al., 2019).

\section{Step 1: Forming the performance matrix for alternatives}

The performance matrix for alternatives is formed through the opinion of experts, who give their opinion about the performance of each element regarding each criterion. Since there is more than one expert, each element of the matrix represents an arithmetic mean of the opinion of all experts.

$$
P M=\left[\begin{array}{ccccc}
p_{11} & \cdots & p_{1 j} & \cdots & p_{1 n} \\
\vdots & & \vdots & & \vdots \\
p_{k 1} & \cdots & p_{k j} & \cdots & p_{k n} \\
\vdots & & \vdots & & \vdots \\
p_{a 1} & \cdots & p_{a j} & \cdots & p_{a n}
\end{array}\right]_{a \times n}
$$

$a$ and $n$ are the number of alternatives and criteria, respectively.

\section{Step 2: Specifying the aspiration and tolerable levels for each criterion $\left(P_{j}^{*}, P_{j}^{-}\right)$}

The aspiration and tolerable levels of all criteria are calculated through Eqs (16) and (17) for different criteria.

$$
P_{j}^{*}=\max _{k} p_{k j} \text { and } P_{j}^{-}=\min _{k} p_{k j} \text {, for benefit criteria }
$$




$$
P_{j}^{*}=\min _{k} p_{k j} \text { and } P_{j}^{-}=\max _{k} p_{k j} \text {, for cost criteria }
$$

Step 3: Calculating the normalised gap $\left(r_{k j}\right)$

Eq (18) is utilised for calculating the normalised gap.

$$
r_{k j}=\left(\left|P_{j}^{*}-p_{k j}\right|\right) /\left(\left|P_{j}^{*}-P_{j}^{-}\right|\right)
$$

Step 4: Computing the average gap $\left(S_{k}\right)$ and the maximum gap $\left(E_{k}\right)$

The general form of $\mathrm{L}_{\mathrm{p}}$-metric, which is utilised in Eqs (20) and (21), is presented in Eq (19) (Duckstein and Opricovic, 1980).

$$
L_{k}^{q}=\left\{\sum_{j=1}^{n}\left[w_{j} \times r_{k j}\right]^{q}\right\}^{1 / q}
$$

The average gap $\left(S_{k}\right)$ and the maximum gap $\left(E_{k}\right)$ are calculated through Eqs (20) and (21), respectively.

$$
\begin{aligned}
& S_{k}=L_{k}^{q=1}=\sum_{j=1}^{n} w_{j} \times r_{k j}, \forall k=\{1,2, \ldots, a\} \\
& E_{k}=L_{k}^{q=\infty}=\max _{j}\left\{w_{j} \times r_{k j} \mid j=1,2, \ldots, n\right\}, \forall k=\{1,2, \ldots, a\} \\
& S^{*}=\min _{k} S_{k} \text { and } S^{-}=\max _{k} S_{k} \\
& E^{*}=\min _{k} E_{k} \text { and } E^{-}=\max _{k} E_{k}
\end{aligned}
$$

Step 5: Computing the index value and Ranking the alternatives

$$
R_{k}=\theta \times\left[\left(S_{k}-S^{*}\right) /\left(S^{*}-S^{-}\right)\right]+(1-\theta) \times\left[\left(E_{k}-E^{*}\right) /\left(E^{*}-E^{-}\right)\right]
$$

$\theta$ and $(1-\theta)$ represent the weight of the strategy of the maximum group utility and the weight of individual regret, respectively. For ranking the alternatives, they should be sorted regarding the $S_{k}$, $E_{k}$, and $R_{k}$ values decreasingly. The result would be three ranking lists. Alternatives $\mathrm{a}_{1}$ and $\mathrm{a}_{2}$ would be the first and second rank if the following conditions are met.

Condition $1, R\left(a_{2}\right)-R\left(a_{1}\right) \geq D R$, where $D R=1 /(a-1)$

Condition 2 is that a should be ranked first in $E$ or/and $S$ list(s). This compromise solution would be stable within a decision-making process, which could be voting by majority rule $(\theta>0.5)$, or consensus $(\theta \approx 0.5)$, or veto $(\theta<0.5)$. If one of these conditions is not met, a set of compromise solutions should be presented based on the following instructions (Krishankumar et al., 2020). 
Both $a_{1}$ and $a_{2}$ would be ranked in the first place if only condition 2 is not met. Alternatives $a_{l}$, $a_{2}, \ldots, a_{r l}$ would be ranked in the first place if condition 1 is not met. The $a_{r l}$ is determined based on $\mathrm{Eq}(26)$.

$$
R\left(a_{r 1}\right)-R\left(a_{1}\right)<D R
$$

\section{Case study}

Dental tourism is an evolving industry, expanding at a rapid pace. The global market of dental tourism is mainly induced due to increased dental anomalies and demand for cosmetic dentistry. Reasonable cost of treatment and better service in destination countries, and prolonged waiting time in the home country of tourists for dental treatment could promote the expansion of the dental tourism market in the near future.

Numerous advances have been made in dentistry science from the starting point of its history in Iran, dating back to about 800 years ago. The founding of the first dental school in the 1930s in Tehran promoted a trend leading to establishing dozens of dental colleges currently training hundreds of dentists each year in different dental specialities. Nowadays, Iran possesses hundreds of dental clinics with trained specialists as their staff, offering a broad range of dental and cosmetic procedures. Some of these procedures are tooth whitening, dental implants, dental veneers, root canal, braces, scaling and root planning, bonding, gum surgery, and tooth extraction. The growing demand for dental procedures has promoted Iranian dentists to extend their dentistry knowledge and expertise. It should be mentioned that Iran, which has up-to-date and the most modern equipment, is among the countries that present top-quality dental services in the world. Modern dental clinics in Iran are mainly allocated in big cities, such as Tehran, Mashhad, Sari, Kish, Shiraz, and Tabriz.

Every year, many tourists choose Iran as their destination for dental services, mainly because of the reasonable cost and the high quality of treatments. The majority of dental tourists visiting Iran are from neighbouring countries such as Iraq, Qatar, Oman, United Arab Emirates, and Azerbaijan. Many Europeans and North Americans also express their willingness to travel to Iran for affordable dental procedures, a costly service in their home countries. For these reasons, many Iranians who live abroad get their dental works done during their visit to their motherland.

The affordable cost of dentistry in Iran results from economic factors like low taxes and costs of living and particularly the dramatically increasing exchange rate of foreign currencies to Iranian Rial, and it most certainly does not infer the low quality of these services. Countless advantages of receiving dental treatment, such as low cost of living, accommodations, and dental care services, visiting hospitable people with colourful culture, and skillful doctors, make Iran an ideal destination for dental tourists. 


\subsection{Problem description}

This study used the predetermined and acknowledged criteria and adopted them for dental tourism. The criteria are extracted from multiple studies that considered a specific aspect of dental tourism. This study selected and justified the most relevant criteria using the opinion of qualified experts. The experts themselves should be carefully selected, having a specific set of characteristics. They should be employees of one of the well-known medical/dental tourism agencies in Iran with more than five years of experience in their position. Also, they should be in constant connection with the customers of the agency so they would be familiar with their mindset. The selected experts were the Assistant Directors, Sales and Marketing Experts, and Assistant Directors and Directors of the Reservations Department of the selected agencies. The details about the selected agencies and the employees who collaborated in the data collection process are presented in Table 2.

Table 2. Characteristics of the selected experts

\begin{tabular}{|c|c|c|c|c|}
\hline Number & Company & Position & Gender & $\begin{array}{c}\text { Years of } \\
\text { experience }\end{array}$ \\
\hline 1 & \multirow{4}{*}{$\begin{array}{c}\text { Aria MedTour } \\
\text { (ariamedtour.com/) }\end{array}$} & Assistant Director & Male & 8 \\
\hline 2 & & Sales and Marketing Expert & Male & 6 \\
\hline 3 & & Sales and Marketing Expert & Male & 7 \\
\hline 4 & & Assistant Director of Reservations Department & Female & 5 \\
\hline 5 & \multirow{4}{*}{$\begin{array}{l}\text { AITO MedTour } \\
\text { (aitomedtour.com/) }\end{array}$} & Assistant Director & Female & 7 \\
\hline 6 & & Sales and Marketing Expert & Male & 5 \\
\hline 7 & & Sales and Marketing Expert & Female & 5 \\
\hline 8 & & Assistant Director of Reservation Department & Male & 6 \\
\hline 9 & \multirow{3}{*}{$\begin{array}{l}\text { Alaedin Travel } \\
\text { (alaedin.travel/en) }\end{array}$} & Assistant Director & Female & 5 \\
\hline 10 & & Sales and Marketing Expert & Female & 6 \\
\hline 11 & & Director of Reservation Department & Male & 5 \\
\hline 12 & \multirow{3}{*}{$\begin{array}{c}\text { Raadina Health } \\
\text { (raadinahealth.com/en/) }\end{array}$} & Assistant Director & Female & 6 \\
\hline 13 & & Sales and Marketing Expert & Male & 6 \\
\hline 14 & & Director of Reservation Department & Male & 5 \\
\hline 15 & \multirow{3}{*}{$\begin{array}{c}\text { Atrina Club } \\
\text { (atrinaclub.com/en) }\end{array}$} & Assistant Director & Male & 5 \\
\hline 16 & & Sales and Marketing Expert & Female & 5 \\
\hline 17 & & Director of Reservation Department & Male & 6 \\
\hline
\end{tabular}

After thorough research and consultancy with the selected experts, Isfahan, Tehran, Shiraz, Mashhad, Yazd, Kish, Rasht, and Sari were selected as potential cities for investigation in the suitability of investing in dental tourism. The mentioned cities seem to have a better profile than other cities regarding dental services and tourism quality. Hence they would be more suitable for investing in dental tourism. In this study, the evaluation of the candidate cities is done through a hybrid MCDM model, combining VIKOR, DANP, and DEMATEL, explored in detail in section 3.

\subsection{Determining the interrelation of criteria}

The DEMATEL approach is used to determine the interrelation of five dimensions and nineteen criteria and forms the INRM using the comparison matrices. Hence, the experts were asked to give their opinion regarding the relations and importance of dimensions and criteria. After collecting the opinion of experts, calculating the arithmetic mean of their opinion and applying the steps of DEMATEL, initial influential matrix, normalised direct-relation, total-influential criteria matrix 
$\left(\mathrm{T}_{\mathrm{C}}\right)$, and total-influential dimensions matrix $\left(\mathrm{T}_{\mathrm{D}}\right)$ are calculated and presented in Tables 3-6, respectively. Finally, the sum of influences given and received on dimensions and criteria and INRM are shown in Table 7 and Fig 2. 
Table 3. Initial influential matrix

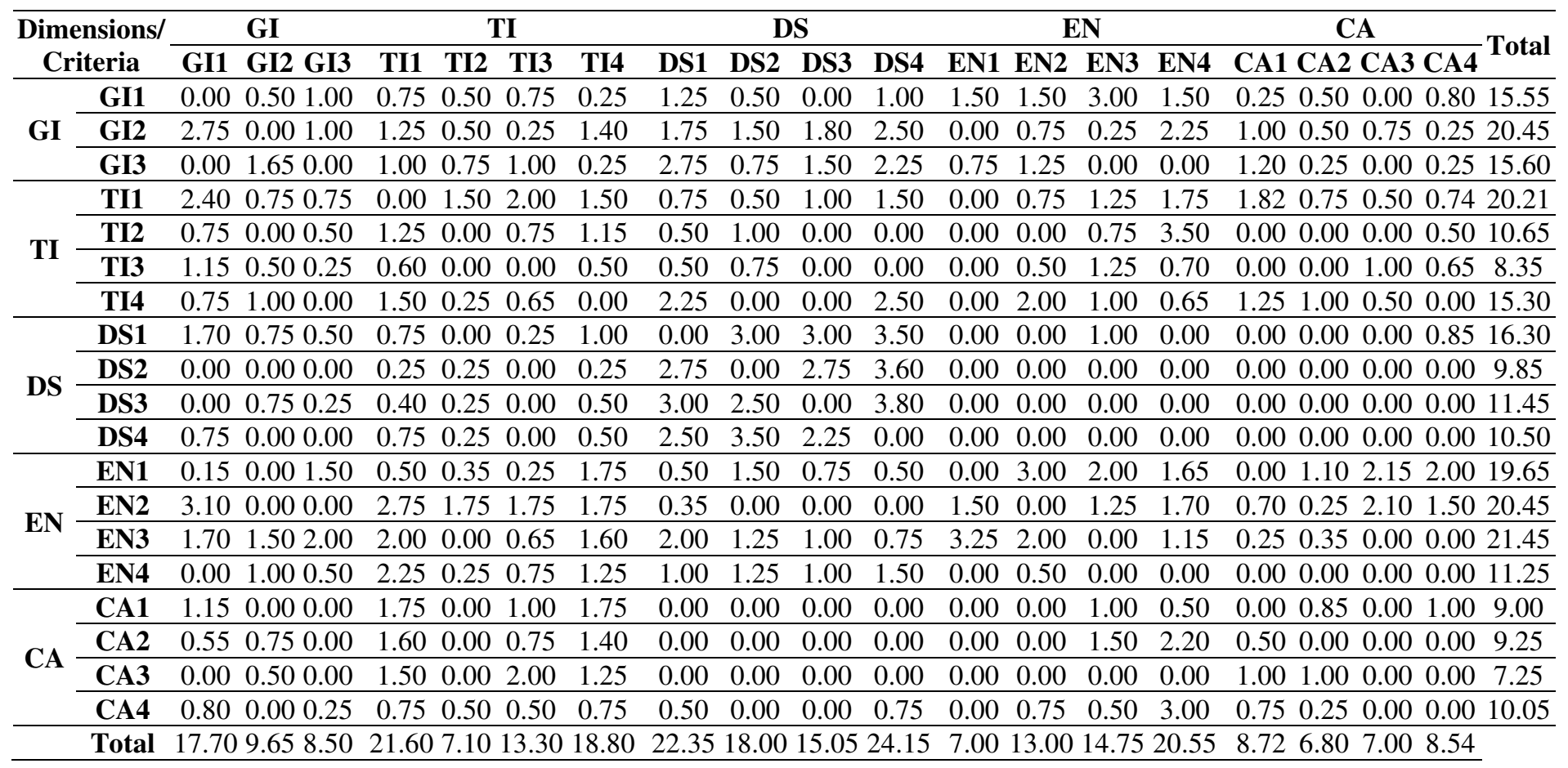


Table 4. Normalised direct-relation

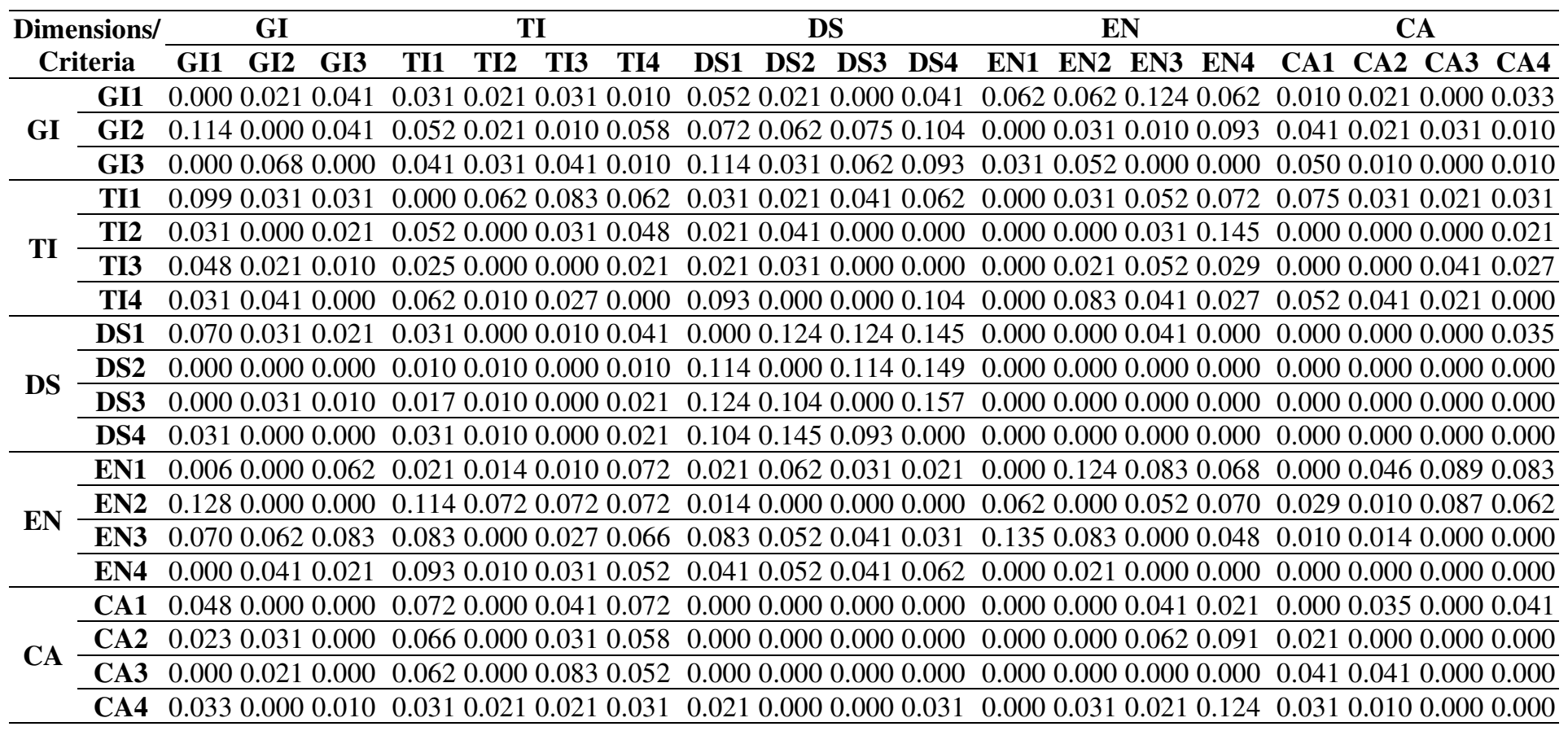


Table 5. Total-influential criteria matrix $\left(T_{C}\right)$

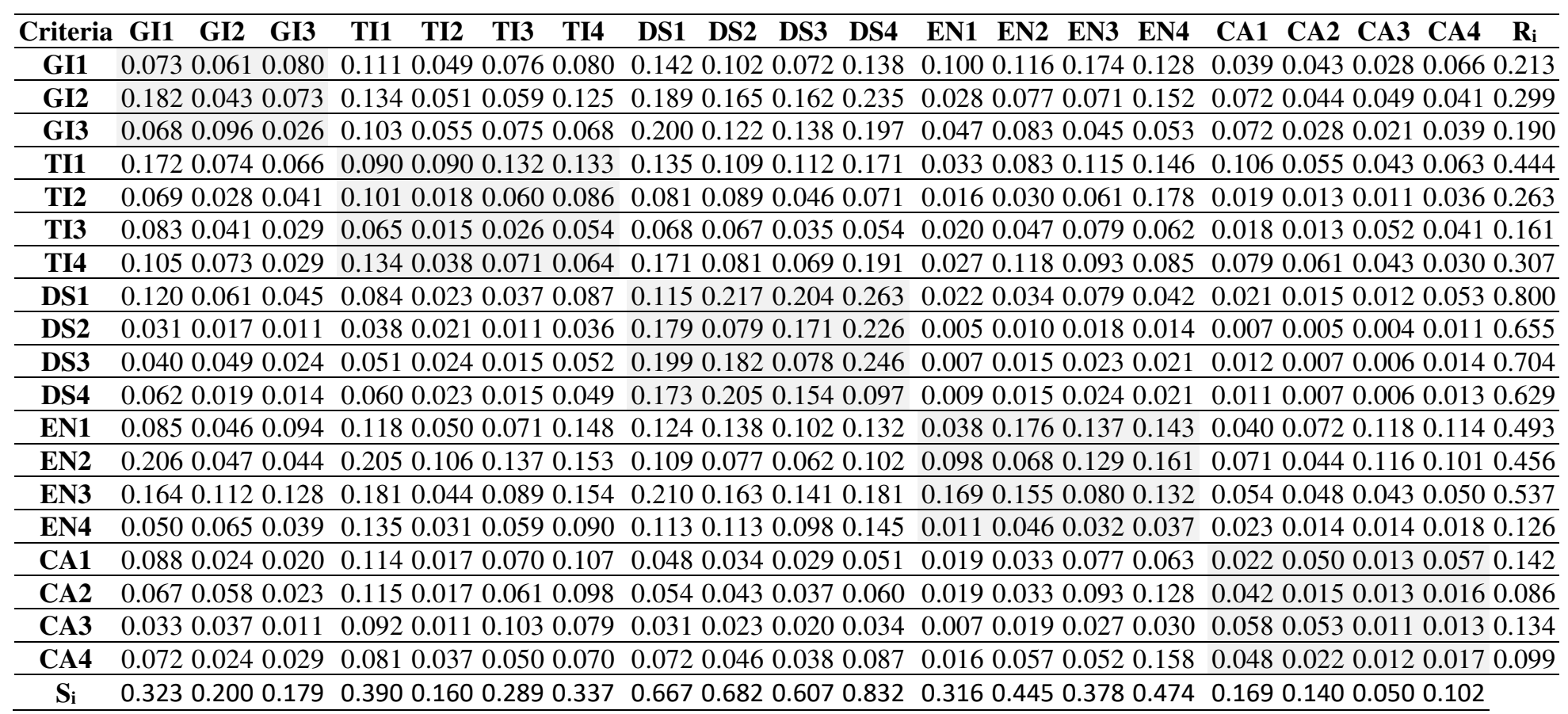


Table 6. Total-influential dimensions matrix $\left(T_{D}\right)$

\begin{tabular}{ccccccc}
\hline Dimensions & GI & TI & DS & EN & CA & $\mathbf{R}_{\mathbf{i}}$ \\
\hline GI & 0.078 & 0.082 & 0.155 & 0.089 & 0.045 & 0.450 \\
\hline TI & 0.068 & 0.073 & 0.097 & 0.075 & 0.043 & 0.355 \\
\hline DS & 0.041 & 0.039 & 0.174 & 0.022 & 0.013 & 0.290 \\
\hline EN & 0.090 & 0.111 & 0.126 & 0.101 & 0.059 & 0.486 \\
\hline CA & 0.040 & 0.070 & 0.044 & 0.052 & 0.029 & 0.236 \\
\hline S $_{\mathrm{i}}$ & 0.317 & 0.376 & 0.596 & 0.339 & 0.188 & - \\
\hline
\end{tabular}

Table 7. Sum of influences given and received on dimensions and criteria

\begin{tabular}{ccccc}
\hline $\begin{array}{c}\text { Dimensions/ } \\
\text { Criteria }\end{array}$ & $\boldsymbol{r}_{\boldsymbol{i}}$ & $\boldsymbol{s} \boldsymbol{i}$ & $\boldsymbol{r}_{\boldsymbol{i}}+\boldsymbol{s}_{\boldsymbol{i}}$ & $\boldsymbol{r}_{\boldsymbol{i}}$ - $\boldsymbol{s}$ \\
\hline GI & 0.450 & 0.317 & 0.767 & 0.133 \\
\hline GI1 & 0.213 & 0.323 & 0.536 & -0.110 \\
\hline GI2 & 0.299 & 0.2 & 0.499 & 0.099 \\
\hline GI3 & 0.190 & 0.179 & 0.369 & 0.011 \\
\hline TI & 0.355 & 0.376 & 0.731 & -0.021 \\
\hline TI1 & 0.444 & 0.39 & 0.834 & 0.054 \\
\hline TI2 & 0.263 & 0.16 & 0.423 & 0.103 \\
\hline TI3 & 0.161 & 0.289 & 0.450 & -0.128 \\
\hline TI4 & 0.307 & 0.337 & 0.644 & -0.030 \\
\hline DS & 0.290 & 0.596 & 0.886 & -0.306 \\
\hline DS1 & 0.800 & 0.667 & 1.467 & 0.133 \\
\hline DS2 & 0.655 & 0.682 & 1.337 & -0.027 \\
\hline DS3 & 0.704 & 0.607 & 1.311 & 0.097 \\
\hline DS4 & 0.629 & 0.832 & 1.461 & -0.203 \\
\hline EN & 0.486 & 0.339 & 0.825 & 0.147 \\
\hline EN1 & 0.493 & 0.316 & 0.809 & 0.177 \\
\hline EN2 & 0.456 & 0.445 & 0.901 & 0.011 \\
\hline EN3 & 0.537 & 0.378 & 0.915 & 0.159 \\
\hline EN4 & 0.126 & 0.474 & 0.600 & -0.348 \\
\hline CA & 0.236 & 0.188 & 0.424 & 0.048 \\
\hline CA1 & 0.142 & 0.169 & 0.311 & -0.027 \\
\hline CA2 & 0.086 & 0.14 & 0.226 & -0.054 \\
\hline CA3 & 0.134 & 0.05 & 0.184 & 0.084 \\
\hline CA4 & 0.099 & 0.102 & 0.201 & -0.003 \\
\hline & & & &
\end{tabular}




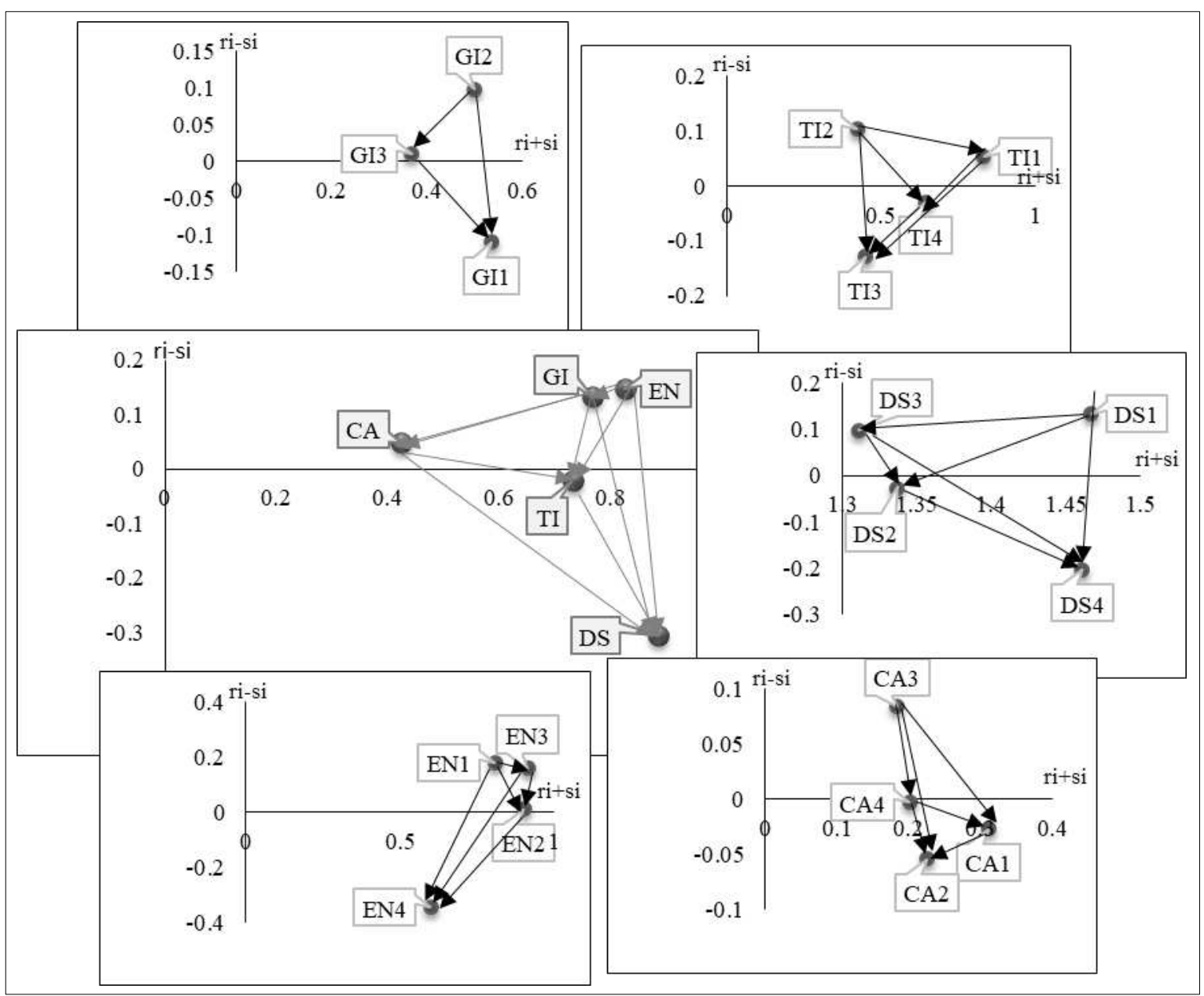

Figure 2. Influential network relations map (INRM)

\subsection{Computing the weights of criteria}

The DANP approach is used for determining the weights of criteria based on the total-influential matrix formed in DEMATEL. After applying the steps of DANP explored in section 3, the totalinfluential criteria matrix $\left(T_{c}\right)$ is computed, and through that, the unweighted supermatrix $\left(W_{c}\right)$, the weighted supermatrix $\left(W_{c}{ }^{*}\right)$, and consequently, local and global weights of dimensions and criteria, which are presented in Tables 8-10, respectively, would be calculated. 
Table 8. Unweighted supermatrix $\left(W_{c}\right)$

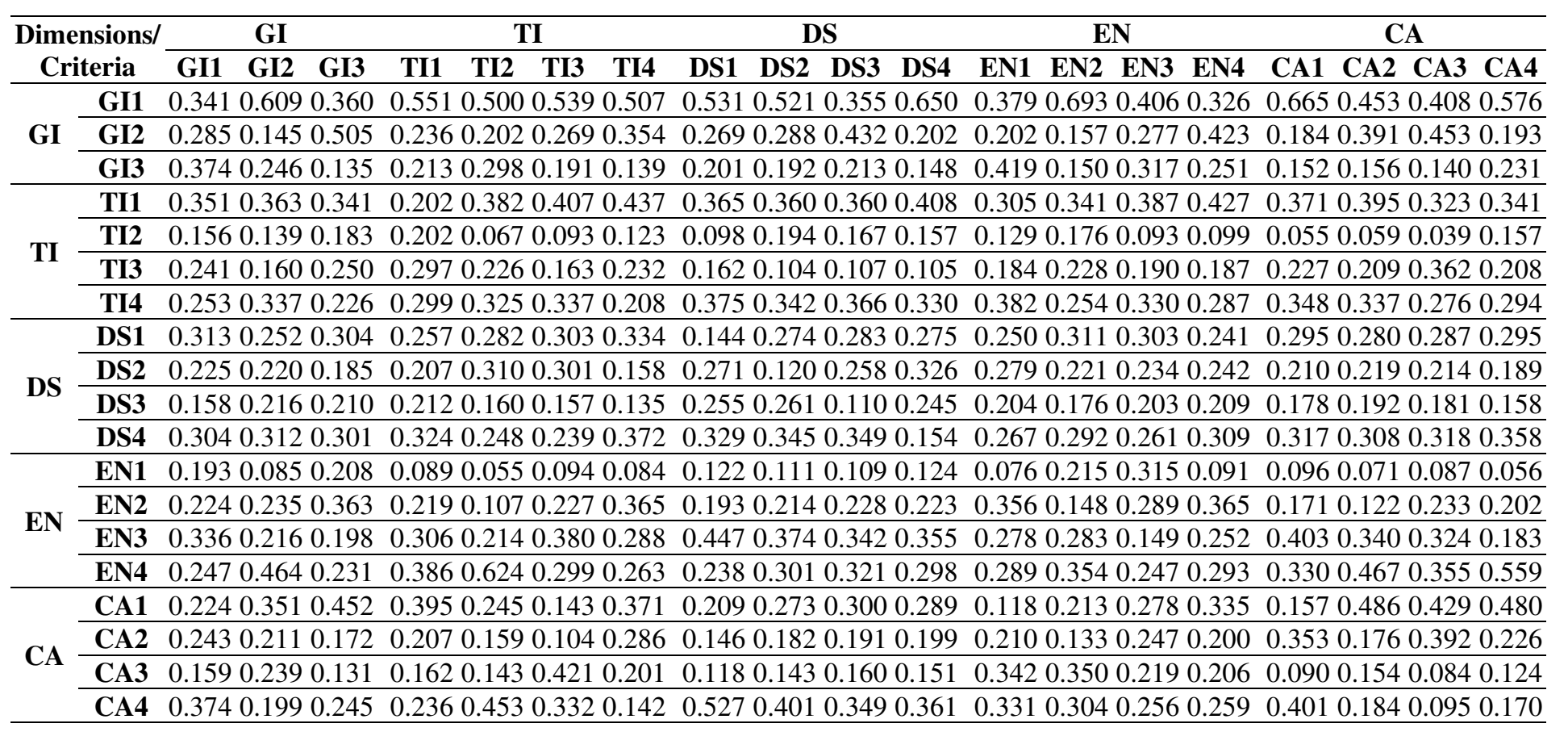


Table 9. The weighted supermatrix $\left(W_{c}^{*}\right)$

\begin{tabular}{|c|c|c|c|c|c|c|}
\hline \multirow{2}{*}{\multicolumn{2}{|c|}{$\begin{array}{c}\text { Dimensions/ } \\
\text { Criteria } \\
\end{array}$}} & $\begin{array}{l}\text { GI } \\
\text { GI2 }\end{array}$ & TI & DS & EN & $\mathbf{C A}$ \\
\hline & & $\begin{array}{lll}\text { GI1 } & \text { GI2 } & \text { GI3 } \\
\end{array}$ & $\begin{array}{lll}\text { TI2 } & \text { TI3 } & \text { TI4 }\end{array}$ & $\begin{array}{llll}\text { DS1 } & \text { DS2 } & \text { DS3 } & \text { DS4 }\end{array}$ & EN1 EN2 EN3 EN4 & CA1 CA2 CA3 CA4 \\
\hline \multirow{3}{*}{ GI } & GI1 & 0.0590 .1050 .062 & 0.1050 .0950 .1030 .097 & 0.0760 .0740 .0500 .093 & 0.0700 .1280 .0750 .060 & 0.1140 .0780 .0700 .099 \\
\hline & GI2 & 0.0490 .0250 .087 & 0.0450 .0380 .0510 .067 & 0.0380 .0410 .0620 .029 & 0.0370 .0290 .0510 .078 & 0.0320 .0670 .0780 .033 \\
\hline & GI3 & 0.0650 .0430 .023 & 0.0410 .0570 .0360 .026 & 0.0290 .0270 .0300 .021 & 0.0780 .0280 .0590 .046 & 0.0260 .0270 .0240 .040 \\
\hline \multirow{4}{*}{ TI } & TI1 & 0.0640 .0660 .062 & 0.0420 .0790 .0840 .090 & 0.0490 .0490 .0490 .055 & 0.0690 .0780 .0880 .097 & 0.1100 .1180 .0960 .102 \\
\hline & TI2 & 0.0290 .0250 .033 & 0.0420 .0140 .0190 .025 & 0.0130 .0260 .0220 .021 & 0.0290 .0400 .0210 .023 & 0.0160 .0180 .0120 .047 \\
\hline & TI3 & 0.0440 .0290 .046 & 0.0610 .0470 .0340 .048 & 0.0220 .0140 .0140 .014 & 0.0420 .0520 .0430 .043 & 0.0670 .0620 .1080 .062 \\
\hline & TI4 & 0.0460 .0620 .041 & 0.0620 .0670 .0700 .043 & 0.0510 .0460 .0490 .044 & 0.0870 .0580 .0750 .065 & 0.1040 .1000 .0820 .088 \\
\hline \multirow{4}{*}{ DS } & DS1 & 0.1080 .0870 .105 & 0.0700 .0770 .0830 .091 & 0.0870 .1650 .1700 .165 & 0.0650 .0800 .0780 .062 & 0.0550 .0530 .0 \\
\hline & DS2 & 0.0780 .0760 .064 & 0.0570 .0850 .0820 .043 & 0.1630 .0720 .1550 .196 & 0.0720 .0570 .0610 .063 & 0.0390 .0410$. \\
\hline & DS3 & 0.0550 .0740 .072 & 440.0430 .037 & 0.1540 .1570 .0660 .147 & 0.0530 .0460 .0 & 0.0330 .0360 \\
\hline & DS4 & 0.1050 .1080 .104 & 0.0890 .0680 .0650 .102 & 0.1980 .2070 .2100 .093 & 0.0690 .0760 .0670 .080 & 0.0590 .0580$. \\
\hline \multirow{4}{*}{$\mathbf{E N}$} & EN1 & 0.0380 .0170 .041 & 0.0190 .0120 .0200 .018 & 0.0090 .0090 .0080 .010 & 0.0160 .0450 .0650 .019 & 0.0210 .0160 .0190 .012 \\
\hline & EN2 & 0.0440 .0470 .072 & 0.0460 .0220 .0480 .077 & 0.0150 .0170 .0180 .017 & 0.0740 .0310 .0600 .076 & 0.0380 .0270$. \\
\hline & EN3 & 0.0670 .0430 .039 & 0.0640 .0450 .0800 .060 & 0.0350 .0290 .0270 .027 & 0.0580 .0590 .0310 .052 & 0.0890 .0750 .0720 .040 \\
\hline & EN4 & 0.0490 .0920 .046 & 0.0810 .1310 .0630 .055 & 0.0180 .0230 .0250 .023 & 0.0600 .0730 .0510 .061 & 0.0730 .1030 .0780 .123 \\
\hline \multirow{4}{*}{$\mathbf{C A}$} & CA1 & 0.0230 .0350 .045 & 0.0470 .0290 .0170 .045 & 0.0090 .0120 .0130 .013 & 0.0140 .0260 .0340 .041 & 0.0190 .0590 .0530 .059 \\
\hline & CA2 & 0.0240 .0210 .017 & 0.0250 .0190 .0130 .034 & 0.0060 .0080 .0080 .009 & 0.0250 .0160 .0300 .024 & 0.0430 .0220 .0480 .028 \\
\hline & CA3 & 0.0160 .0240 .013 & 0.0190 .0170 .0510 .024 & 0.0050 .0060 .0070 .007 & 0.0410 .0420 .0260 .025 & 0.0110 .0190 .0100 .015 \\
\hline & CA4 & 0.0380 .0200 .025 & 0.0280 .0540 .0400 .017 & 0.0230 .0180 .0150 .016 & 0.0400 .0370 .0310 .031 & 0.0490 .0230 .0120 .021 \\
\hline
\end{tabular}


Table 10. Local and global weights of dimensions and criteria

\begin{tabular}{cccc}
\hline $\begin{array}{c}\text { Dimensions/ } \\
\text { Criteria }\end{array}$ & $\begin{array}{c}\text { Local weight } \\
\text { (based on DANP) }\end{array}$ & $\begin{array}{c}\text { Global weight } \\
\text { (based on DANP) }\end{array}$ & Rank \\
\hline GI & $\mathbf{0 . 1 6 5}$ & & $\mathbf{3}$ \\
\hline GI1 & 0.493 & 0.082 & 5 \\
\hline GI2 & 0.288 & 0.047 & 9 \\
\hline GI3 & 0.219 & 0.036 & 12 \\
\hline TI & $\mathbf{0 . 1 8 5}$ & & $\mathbf{2}$ \\
\hline TI1 & 0.361 & 0.067 & 6 \\
\hline TI2 & 0.126 & 0.025 & 16 \\
\hline TI3 & 0.202 & 0.036 & 13 \\
\hline TI4 & 0.311 & 0.057 & 7 \\
\hline DS & $\mathbf{0 . 4 1 0}$ & & $\mathbf{1}$ \\
\hline DS1 & 0.278 & 0.107 & 2 \\
\hline DS2 & 0.231 & 0.098 & 3 \\
\hline DS3 & 0.191 & 0.085 & 4 \\
\hline DS4 & 0.300 & 0.12 & 1 \\
\hline EN & $\mathbf{0 . 1 5 5}$ & & $\mathbf{4}$ \\
\hline EN1 & 0.120 & 0.02 & 17 \\
\hline EN2 & 0.236 & 0.038 & 11 \\
\hline EN3 & 0.298 & 0.046 & 10 \\
\hline EN4 & 0.346 & 0.051 & 8 \\
\hline CA & $\mathbf{0 . 0 8 6}$ & & $\mathbf{5}$ \\
\hline CA1 & 0.303 & 0.026 & 14 \\
\hline CA2 & 0.212 & 0.018 & 18 \\
\hline CA3 & 0.189 & 0.016 & 19 \\
\hline CA4 & 0.296 & 0.026 & 15 \\
\hline & & &
\end{tabular}

\subsection{Ranking of alternatives}

After determining the weights of criteria through DANP, the selected cities are evaluated based on the opinion of the experts and regarding the mentioned five dimensions and nineteen criteria through VIKOR. The questionnaire of this section is filled with the opinion of experts using numbers 0 to 10 , showing the worst and best conditions, respectively. Then the average performance score of each potential location is used in the application of the VIKOR method to determine the aspired level gaps and the performance of each alternative. The value of $v$ in the VIKOR method was set to 0.5 , considering the maximum group ability and individual regret in the opinion of experts. The final results of the VIKOR method are presented in Table 11. 
Table 11. VIKOR results

\begin{tabular}{|c|c|c|c|c|c|c|c|c|c|c|}
\hline Dimension & iteria & Esfahan & Shiraz & Kish & Tehran & Mashhad & Yazd & Tabriz & Rasht & Sari \\
\hline \multirow{3}{*}{ GI } & GI1 & 0.0554 & 0.0000 & 0.0536 & 0.0089 & 0.0304 & 0.0714 & 0.0268 & 0.0554 & 0.0822 \\
\hline & GI2 & 0.0354 & 0.0000 & 0.0295 & 0.0082 & 0.0236 & 0.0354 & 0.0189 & 0.0295 & 0.0471 \\
\hline & GI3 & 0.0128 & 0.0000 & 0.0233 & 0.0058 & 0.0000 & 0.0292 & 0.0070 & .0152 & .0362 \\
\hline \multirow{4}{*}{ TI } & TI1 & 0.0182 & 0.0000 & 0.0182 & 0.0000 & 0.0182 & 0.0425 & 0.0049 & .0292 & .0668 \\
\hline & TI2 & 0.0145 & 0.0000 & 0.0138 & 0.0103 & 0.0069 & 0.0172 & 0.0062 & 0.0200 & 0.0248 \\
\hline & TI3 & 0.0357 & 0.0045 & 0.0156 & 0.0000 & 0.0067 & 0.0045 & 0.0223 & 0.0134 & 0.0290 \\
\hline & TI4 & 0.0382 & 0.0076 & 0.0267 & 0.0000 & 0.0458 & 0.0267 & 0.0343 & 0.0534 & 0.0572 \\
\hline \multirow{4}{*}{ DS } & DS1 & 0.0578 & 0.0000 & 0.0578 & 0.0433 & 0.1 & 0.0867 & 0.0867 & 0.1011 & 0.1069 \\
\hline & DS2 & 0.0550 & 0.0000 & 0.0500 & 0.0425 & 0.0500 & 0.0750 & 0.0800 & 0.0901 & 0.0976 \\
\hline & DS3 & 0.0400 & 0.0000 & 0.0325 & 0.0250 & 0.0250 & 0.0500 & 0.0725 & 0.0700 & 0.0849 \\
\hline & DS4 & 0.0647 & 0.0000 & 0.0585 & 0.0462 & 0.0308 & 0.0462 & 0.1078 & 0.1201 & 0.1109 \\
\hline \multirow{4}{*}{ EN } & EN1 & 0.0173 & 0.0102 & 0.0134 & 0.0167 & 0.0134 & 0.0199 & 0.0134 & 0.0000 & 0.0013 \\
\hline & EN2 & 0.0377 & 0.0298 & 0.0298 & 0.0298 & 0.0298 & 0.0220 & 0.0251 & 0.0047 & 0.0000 \\
\hline & EN3 & 0.0268 & 0.0293 & 0.0209 & 0.0461 & 0.0377 & 0.0126 & 0.0293 & 0.0168 & 0.0000 \\
\hline & EN4 & 0.0426 & 0.0248 & 0.0275 & 0.0509 & 0.0275 & 0.0124 & 0.0481 & 0.0206 & 0.0000 \\
\hline \multirow{4}{*}{ CA } & CA1 & 0.0062 & 0.0052 & 0.0258 & 0.0103 & 0.0052 & 0.0000 & 0.0248 & 0.0196 & 0.0145 \\
\hline & CA2 & 0.0181 & 0.0000 & 0.0105 & 0.0070 & 0.0049 & 0.0035 & 0.0146 & 0.0063 & 0.0070 \\
\hline & CA3 & 0.0062 & 0.0144 & 0.0124 & 0.0082 & 0.0066 & 0.0041 & 0.0165 & 0.0008 & 0.0000 \\
\hline & CA4 & 0.0049 & 0.0165 & 0.0206 & 0.0165 & 0.0165 & 0.0000 & 0.0190 & 0.0082 & 0.0256 \\
\hline $\mathbf{S}$ & & 0.587408 & 0.14233 & 0.540494 & 0.37586 & 0.436719 & 0.559 & .6582( & 0.6742 & 0.791851 \\
\hline $\mathbf{E}$ & & 0.064668 & 202 & 0.05850 & 0.050883 & 0.05777 & 0.086655 & 0.10778 & 0.12009 & 0.110859 \\
\hline $\mathbf{R}$ & & 0.535592 & 0 & 0.465363 & 0.29639 & 0.381383 & 0.6356 & 0.82889 & 0.90944 & 0.948829 \\
\hline
\end{tabular}

\subsection{Results}

The results of this study could be divided into three parts. The first part would determine INRM. The INRM specifies which of the dimensions or criteria have influences on each other. For example, according to Table 7 and Fig 2, dimension EN influences dimensions GI, TI, DS, and CA. This relationship would be presented with an arrow from EN to GI, TI, DS, and CA (EN $\rightarrow\{$ GI, TI, DS, CA $\}$ ). The rest of the relationships following the same rule of arrows from influencer to the influenced dimensions or criteria could be determined from Fig 2.

Specification of these relationships helps managers in the decision-making process. For example, they would understand that they should attend to improve the condition of a potential location in $\mathrm{EN}$, then GI, CA, TI, and finally DS dimensions. Moreover, in order to enhance the performance of a potential location regarding DS4, they should first improve the performance of DS2. Hence, managers of the dental tourism division could use the INRM of the DEMATEL method to prioritise the criteria that they need to improve and present market strategies to attract tourists based on that.

The second part of the results is related to the weights of criteria. Table 10 represents the weights and ranking of the specified five dimensions and nineteen criteria. Moreover, it shows that the DS4, DS1, DS2, and DS3 have the highest global weights, respectively, and subsequently are the most significant criteria in ranking potential locations. DS is determined as the most influential dimension in the dental tourism industry, indicating that the first criteria that dental tourists consider in destination selection are related to the quality of dental clinics and equipment and dental care. 
Finally, the last part of the results determines the final ranking of the potential locations for investment in dental tourism. The final ranking is determined according to the information in Table 11 , and the final steps of the VIKOR. The VIKOR calculates the utility, regret, and ranking measures which are represented by $R, E$, and $S$, respectively, and ranks the alternatives according to the conditions mentioned in step 5 of the VIKOR method explored in section 3.4. The final results and ranking of the alternatives considering the ascending order of $R, E$, and $S$ are presented in Table 12. According to the information in Table 12, Shiraz is determined to the best location for investment in dental tourism by satisfying the following conditions.

Condition $1, \mathrm{R}_{\text {(Tehran) }}-\mathrm{R}_{(\text {Shiraz })}=0.296, \mathrm{DR}=1 /(9-1)=0.125$, and $0.296>0.125$

Condition 2, Shiraz is ranked first in $E$ and $S$ lists.

Table 12. Ranking by VIKOR

\begin{tabular}{ccccccc}
\hline Potential locations & $\boldsymbol{S}$ & Rank by $\boldsymbol{S}$ & $\boldsymbol{E}$ & Rank by $\boldsymbol{E}$ & $\boldsymbol{R}$ & Rank by $\boldsymbol{R}$ \\
\hline Esfahan & 0.587408 & 6 & 0.064668 & 5 & 0.535592 & 5 \\
\hline Shiraz & 0.14233 & 1 & 0.02983 & 1 & 0 & 1 \\
\hline Kish & 0.540494 & 4 & 0.058509 & 4 & 0.465363 & 4 \\
\hline Tehran & 0.37586 & 2 & 0.050883 & 2 & 0.29639 & 2 \\
\hline Mashhad & 0.436719 & 3 & 0.05777 & 3 & 0.381383 & 3 \\
\hline Yazd & 0.559116 & 5 & 0.086655 & 6 & 0.6356 & 6 \\
\hline Tabriz & 0.658209 & 7 & 0.10778 & 7 & 0.828894 & 7 \\
\hline Rasht & 0.674215 & 8 & 0.120097 & 9 & 0.909444 & 8 \\
\hline Sari & 0.791851 & 9 & 0.110859 & 8 & 0.948829 & 9 \\
\hline
\end{tabular}

Shiraz has been selected as the best location for investment in dental tourism, meaning that it had the best performance in most of the criteria, including all of the criteria in GI and DS dimensions and two and one criteria in TI and CA dimensions, respectively. In other words, Shiraz is the most suitable city for investment in dental tourism through having the best performance in DS and GI dimensions, which are also ranked the first and third most important dimensions. Regardless of that, it has worse performance than other cities in EN, CA, and TI, respectively.

Even though the first ranked location has the best performance in most of the criteria, there are some criteria where there are gaps between the performance of the selected city and the best performance level. The most significant criteria based on the value of the gaps are EN2, EN3, EN4, CA4, CA3, EN1, TI4, CA1, and TI3. In order to reduce the existing gaps in some criteria for the selected city, the city officials of Shiraz could try to improve the conditions of the city in criteria such as EN2, EN3, and EN4 being traffic congestion and air and noise pollution, safety (crime rates), and attractiveness of the city, respectively. These criteria could be improved and reach the best conditions by some strategies or policies, so the selected location becomes the perfect one.

Since the dimension EN has the most significant gaps among other criteria, and according to Fig 2 , its change can influence some other dimensions, finding strategies and policies that could improve the condition of this criteria would be the most reasonable idea for the managers of this industry. According to the weights of criteria, the order of the criteria based on the priority to come up with solutions would be EN2, EN3, EN4, and EN1, and according to the INRM, the order would 
be EN1, EN3, EN2, and EN4. Accordingly, in a compromised set, the best criteria to come up with strategies or policies to improve the performance of cities would be EN2 and EN3.

\section{Conclusion}

Medical tourism is a comparatively novel concept in the healthcare sector, and it has one of the fastest-growing rates in tourism markets worldwide. Dental tourism, as a subset of medical tourism, is expanding all around the world, while it has a faster pace in developing countries. This research presented a decision-making model using a hybrid MCDM approach combining DANP and VIKOR. First, the DEMATEL is used to determine the interrelation of criteria, and then, the DANP is employed to calculate their weights. Finally, VIKOR is used to evaluate the suitability of different cities for investment in dental tourism and determine the potential areas of the selected cities that require enhancement. Moreover, the present study specifies the gaps of cities in different criteria and discusses measures that could reduce the pressure of these gaps.

The results of the study indicate that the dental facilities and service (DS) is the most critical dimension in dental tourism, and reputation of hospital/facility and doctors (DS4), dental clinics with certification/accreditation scheme (DS1), and qualified and competent dental professionals (DS2) are the most important criteria for analysing the suitability of cities for dental tourism investment. Finally, Shiraz is selected as the most suitable city for investment in dental tourism, indicating that it has the best or almost the best condition in most of the criteria. The results of this study give a deep understanding of the current conditions and the potentials of the selected cities of Iran to dental tourism management parties and investors in how to decide on a suitable location and to use different strategies for improving the condition of the selected city in the best way possible. Hence, investors can save time and money by choosing the most suitable city for the purpose of their work.

\section{Compliance with ethical standards}

Conflict of interest The authors declare that they have no conflict of interest. 


\section{References}

Adams, K., Snyder, J., Crooks, V.A., Berry, N.S., 2018. A critical examination of empowerment discourse in medical tourism: The case of the dental tourism industry in Los Algodones, Mexico. Globalization and Health 14, 1-10. https://doi.org/10.1186/s12992-018-0392-3

Adams, K., Snyder, J., Crooks, V.A., Berry, N.S., 2017. "Stay cool, sell stuff cheap, and smile": Examining how reputational management of dental tourism reinforces structural oppression in Los Algodones, Mexico. Social Science and Medicine 190, 157-164. https://doi.org/10.1016/j.socscimed.2017.08.028

Ahmadimanesh, F., Paydar, M.M., Asadi-Gangraj, E., 2019. Designing a mathematical model for dental tourism supply chain. Tourism Management 75, 404-417. https://doi.org/10.1016/j.tourman.2019.06.001

Alizadeh, M., Sharbafi, F., Paydar, M.M., 2020. A bi-objective natural disaster blood supply chain network considering blood transfusion: A case study in Babol. International Journal of Industrial Engineering and Management Science 7, 20-40.

Alleman, B.W., Luger, T., Reisinger, H.S., Martin, R., Horowitz, M.D., Cram, P., 2011. Medical tourism services available to residents of the United States. Journal of General Internal Medicine 26, 492-497. https://doi.org/10.1007/s11606-010-1582-8

Ashtiani, M., Abdollahi Azgomi, M., 2016. Trust modeling based on a combination of fuzzy analytic hierarchy process and fuzzy VIKOR. Soft Computing 20, 399-421. https://doi.org/10.1007/s00500-014-1516-1

Beerli, A., Martín, J.D., 2004. Factors influencing destination image. Annals of Tourism Research 31, 657-681. https://doi.org/10.1016/j.annals.2004.01.010

Chen, S.-H., Lin, W.-T., 2018. Analyzing determinants for promoting emerging technology through intermediaries by using a DANP-based MCDA framework. Technological Forecasting and Social Change 131, 94-110. https://doi.org/10.1016/j.techfore.2017.09.019

Chiu, W.-Y., Tzeng, G.-H., Li, H.-L., 2013. A new hybrid MCDM model combining DANP with VIKOR to improve e-store business. Knowledge-Based Systems 37, 48-61. https://doi.org/10.1016/j.knosys.2012.06.017

Dinçer, H., Hošková-Mayerová, Š., Korsakienė, R., Yüksel, S., 2020. IT2-based multidimensional evaluation approach to the signaling: investors' priorities for the emerging industries. Soft Computing 24, 13517-13534. https://doi.org/10.1007/s00500-019-04288-6

Duckstein, L., Opricovic, S., 1980. Multiobjective optimization in river basin development. Water Resources Research 16, 14-20. https://doi.org/10.1029/WR016i001p00014

Elliott-Smith, S., 2010. Dental Tourism: An (examination) room with a view.

Esiyok, B., Çakar, M., Kurtulmuşoğlu, F.B., 2017. The effect of cultural distance on medical tourism. Journal of Destination Marketing and Management 6, 66-75. https://doi.org/10.1016/j.jdmm.2016.03.001

Fabisiak, L., 2018. Web service usability analysis based on user preferences. Journal of Organizational and End User Computing 30, 1-13. https://doi.org/10.4018/JOEUC.2018100101

Fetscherin, M., Stephano, R.M., 2016. The medical tourism index: Scale development and validation. Tourism Management 52 539-556. https://doi.org/10.1016/j.tourman.2015.08.010

Ganguli, S., Ebrahim, A.H., 2017. A qualitative analysis of Singapore's medical tourism competitiveness. Tourism Management Perspectives 21, 74-84. 
https://doi.org/10.1016/j.tmp.2016.12.002

Han, H., Hyun, S.S., 2015. Customer retention in the medical tourism industry: Impact of quality, satisfaction, trust, and price reasonableness. Tourism Management 46, 20-29. https://doi.org/10.1016/j.tourman.2014.06.003

Heung, V.C.S., Kucukusta, D., Song, H., 2011. Medical tourism development in Hong Kong: An assessment of the barriers. Tourism Management 32, 995-1005. https://doi.org/10.1016/j.tourman.2010.08.012

Horowitz, M.D., Rosensweig, J.A., Jones, C.A., 2007. Medical tourism: Globalization of the healthcare marketplace. MedGenMed Medscape General Medicine 9, 33.

Jaapar, M., Musa, G., Moghavvemi, S., Saub, R., 2017. Dental tourism: Examining tourist profiles, motivation and satisfaction. Tourism Management 61, 538-552. https://doi.org/10.1016/j.tourman.2017.02.023

Kamath, K., Hugar, S., Kumar, V., Gokhale, N., Uppin, C., Hugar, S.S., 2015. The business and pleasure of teeth: Dental tourism. International Journal of Contemporary Dental and Medical Reviews 2-5. https://doi.org/10.15713/ins.ijcdmr.82

Khatwani, G., Srivastava, P.R., 2018. Impact of information technology on information search channel selection for consumers. Journal of Organizational and End User Computing 30, 6380. https://doi.org/10.4018/JOEUC.2018070104

Kovacs, E., Szocska, G., 2013. Vacation for your teeth' - Dental tourists in Hungary from the perspective of Hungarian dentists. British Dental Journal 215, 415-418. https://doi.org/10.1038/sj.bdj.2013.995

Krishankumar, R., Premaladha, J., Ravichandran, K.S., Sekar, K.R., Manikandan, R., Gao, X.Z., 2020. A novel extension to VIKOR method under intuitionistic fuzzy context for solving personnel selection problem. Soft Computing 24, 1063-1081. https://doi.org/10.1007/s00500-019-03943-2

Lee, H.K., Fernando, Y., 2015. The antecedents and outcomes of the medical tourism supply chain. Tourism Management 46, 148-157. https://doi.org/10.1016/j.tourman.2014.06.014

Li, M., Li, Y., Peng, Q., Wang, J., Yu, C., 2020. Evaluating community question-answering websites using interval-valued intuitionistic fuzzy DANP and TODIM methods. Applied Soft Computing 106918. https://doi.org/10.1016/j.asoc.2020.106918

Liou, J.J.H., Tzeng, G.H., Chang, H.C., 2007. Airline safety measurement using a hybrid model. Journal of Air Transport Management 13, 243-249. https://doi.org/10.1016/j.jairtraman.2007.04.008

Lovelock, B., Lovelock, K., Lyons, K., 2018. The impact of outbound medical (dental) tourism on the generating region: New Zealand dental professionals' perspectives. Tourism Management 67, 399-410. https://doi.org/10.1016/j.tourman.2018.02.001

Moghimehfar, F., Nasr-Esfahani, M.H., 2011. Decisive factors in medical tourism destination choice: A case study of Isfahan, Iran and fertility treatments. Tourism Management 32, 14311434. https://doi.org/10.1016/j.tourman.2011.01.005

Momeni, K., Janati, A., Imani, A., Khodayari-Zarnaq, R., 2018. Barriers to the development of medical tourism in East Azerbaijan province, Iran: A qualitative study. Tourism Management 69, 307-316. https://doi.org/10.1016/j.tourman.2018.05.007

Nexhipi, O., 2018. Medical Tourism Management Challenges - The Case of Dental Tourism in Albania. European Journal of Interdisciplinary Studies 4, 80. https://doi.org/10.26417/ejis.v4i1.p80-86

Nilashi, M., Samad, S., Manaf, A.A., Ahmadi, H., Rashid, T.A., Munshi, A., Almukadi, W., 
Ibrahim, O., Hassan Ahmed, O., 2019. Factors influencing medical tourism adoption in Malaysia: A DEMATEL-Fuzzy TOPSIS approach. Computers and Industrial Engineering 137, 106005. https://doi.org/10.1016/j.cie.2019.106005

Oltean, F.D., Gabor, M.R., Stăncioiu, A.F., Kardos, M., Marta, K., Marinescu, R.C., 2020. Aspects of marketing in dental tourism-Factor of sustainable development in Romania. Sustainability (Switzerland) 12, 1-13. https://doi.org/10.3390/su12104320

Opricovic, S., Tzeng, G.H., 2007. Extended VIKOR method in comparison with outranking methods. European Journal of Operational Research 178, 514-529. https://doi.org/10.1016/j.ejor.2006.01.020

Österle, A., Balázs, P., Delgado, J., 2009. Travelling for teeth: Characteristics and perspectives of dental care tourism in Hungary. British Dental Journal 206, 425-428. https://doi.org/10.1038/sj.bdj.2009.308

Pan, T.J., Chen, W.C., 2014. Chinese medical tourists - their perceptions of Taiwan. Tourism Management 44, 108-112. https://doi.org/10.1016/j.tourman.2014.02.008

Pourmehdi, M., Paydar, M.M., Asadi-Gangraj, E., 2021. Reaching sustainability through collection center selection considering risk: using the integration of Fuzzy ANP-TOPSIS and FMEA. Soft Computing 1-15. https://doi.org/10.1007/s00500-021-05786-2

Reddy, S.G., York, V.K., Brannon, L.A., 2010. Travel for treatment: Students' perspective on medical tourism. International Journal of Tourism Research 12, 510-522. https://doi.org/10.1002/jtr.769

Saaty, T.L., Vargas, L.G., 2006. Decision making with the analytic network process. Springer.

Si, S.-L., You, X.-Y., Liu, H.-C., Zhang, P., 2018. DEMATEL Technique: A Systematic Review of the State-of-the-Art Literature on Methodologies and Applications. Mathematical Problems in Engineering 2018, 1-33. https://doi.org/10.1155/2018/3696457

Tham, A., 2018. Sand, surgery and stakeholders: A multi-stakeholder involvement model of domestic medical tourism for Australia's Sunshine Coast. Tourism Management Perspectives 25, 29-40. https://doi.org/10.1016/j.tmp.2017.11.002

Titiyal, R., Bhattacharya, S., Thakkar, J.J., 2019. The distribution strategy selection for an e-tailer using a hybrid DANP VIKOR MCDM model. Benchmarking 26, 395-433. https://doi.org/10.1108/BIJ-01-2018-0018

Tourism Research and Marketing, 2006. Medical tourism: a global analysis: a report by Tourism research and marketing. Atlas.

Turner, L., 2008. Cross-border dental care: 'Dental tourism' and patient mobility. British Dental Journal 204, 553-554. https://doi.org/10.1038/sj.bdj.2008.403

Ungureanu, M.I., Mocean, F., 2015. What do patients take into account when they choose their dentist? Implications for quality improvement. Patient Preference and Adherence 9, 17151720. https://doi.org/10.2147/PPA.S94310

Wachter, R.M., 2006. The "Dis-location" of U.S. Medicine — The Implications of Medical Outsourcing. New England Journal of Medicine 354, 661-665. https://doi.org/10.1056/nejmp058258

Whittaker, A., 2008. Pleasure and pain: Medical travel in Asia. Global Public Health 3, 271-290. https://doi.org/10.1080/17441690701463936

Wong, K.M., Musa, G., 2012. Medical tourism in Asia: Thailand, Singapore, Malaysia, and India. Medical Tourism: The Ethics, Regulation, and Marketing of Health Mobility 167-186. https://doi.org/10.4324/9780203109458

Wu, C.H., Yuan, Y.H., Tsai, S.B., 2020. Using the DEMATEL model to expose core causal items 
of LibQUAL for improving library service quality: from the perspective of big data. Soft Computing 24, 5729-5739. https://doi.org/10.1007/s00500-019-04308-5

Yu, J.Y., Ko, T.G., 2012. A cross-cultural study of perceptions of medical tourism among Chinese, Japanese and Korean tourists in Korea. Tourism Management 33, 80-88. https://doi.org/10.1016/j.tourman.2011.02.002

Zhang, L.Z., Mouritsen, M., Miller, J.R., 2019. Role of perceived value in acceptance of "bring your own device" policy. Journal of Organizational and End User Computing 31, 65-80. https://doi.org/10.4018/JOEUC.2019040104 